\title{
Effects of a 10-week multimodal exercise program on physical and cognitive function of nursing home residents: a psychomotor intervention pilot study
}

\author{
Catarina Pereira $^{1,2}$ (i) $\cdot$ Hugo $\operatorname{Rosado}^{1} \cdot$ Ana Cruz-Ferreira ${ }^{1,2} \cdot$ José Marmeleira $^{1,2}$
}

Received: 21 May 2017 / Accepted: 17 July 2017

(C) Springer International Publishing AG 2017

\begin{abstract}
Background Nursing home institutionalization tends to exacerbate loss of functioning.

Aims Examine the feasibility and the effect of a psychomotor intervention - a multimodal exercise program promoting simultaneous cognitive and motor stimulation-on the executive (planning ability and selective attention) and physical function of nursing home residents.

Methods Seventeen participants engaged in a 10-week multimodal exercise program and 17 maintained usual activities.

Results Exercise group improved planning ability (25$32 \%$ ), selective attention (19-67\%), and physical function [aerobic endurance, lower body strength, agility, balance, gait, and mobility (19-41\%)], corresponding to an effect size ranging from 0.29 (small) to 1.11 (high), $p<0.05$.

Discussion The multimodal exercise program was feasible and well tolerated. The program improved executive and physical functions of the nursing home residents, reverting the usual loss of both cognitive and motor functioning in older adult institutionalized.

Conclusions Multimodal exercise programs may help to maintain or improve nursing home residents' functioning.
\end{abstract}

Keywords Elderly $\cdot$ Executive function · Planning ability $\cdot$ Attention $\cdot$ Physical function

Catarina Pereira

clnp@uevora.pt

1 Departamento de Desporto e Saúde, Escola de Ciências e Tecnologia, Universidade de Évora, Colégio Luís António Verney, Rua Romão Ramalho 59, 7000-671 Évora, Portugal

2 Research Centre in Sports Sciences, Health Sciences and Human Development (CIDESD), Vila Real, Portugal

\section{Introduction}

The number of people over the age of 60 has increased, and it is expected to double by 2050 [1] as are old-age dependency $[1,2]$. Nursing home admission has become a social answer to older adults' care needs [3]. However, this tends to exacerbate the usual disability and dependence associated with the ageing process [4, 5]. According to Volkers and Scherder [6] institutionalized nursing home residents show mainly sedentary or passive behavior. This lack of stimulation and activity has a negative impact on physical and cognitive functioning (including executive function) $[5,6]$ which, in turn, is associated with falls and injuries, and increased disability/dependence in the performance of activities of daily living $[5,7,8]$. These issues are intrinsically connected with quality of life $[9,10]$ and one of the main wishes of nursing home residents and their care providers is to revert the usual disability, and dependence trajectory [11].

The research community has been looking for effective solutions to these problems highlighting the health and well-being relevance of physical activity [12]. Several studies have shown that physical exercise programs have a beneficial and effective impact on the health, and on physical and cognitive functioning of frail older adults [13]. Cognitive programs also have benefits for these persons $[14,15]$. However, recent research suggests that multimodal programs, which combine different types of exercises such as physical and cognitive, may have additional benefits [16-18]. Nonetheless, only a few studies have focused on this matter, specifically targeting older adults institutionalized.

Despite the proven benefits of exercise programs, an obstacle to older adults' adherence to such programs is their inability to accomplish each session without stopping [19]. 